\title{
Phosphorylated STAT3 Measurement
}

National Cancer Institute

\section{Source}

National Cancer Institute. Phosphorylated STAT3 Measurement. NCI Thesaurus. Code C156521.

The determination of the amount of phosphorylated STAT 3 present in a sample. 